\title{
How Employees Choose their Commuting Transport Mode: Analysis Using the Stimulus-Organism-Response Model
}

\author{
Ludfi Djakfar $\mathbb{D}^{1},{ }^{1}$ Melchior Bria $\mathbb{D}^{1},{ }^{1,2}$ and Achmad Wicaksono $\mathbb{D}^{1}$ \\ ${ }^{1}$ Department of Civil Engineering, University of Brawijaya, Malang, East Java 65145, Indonesia \\ ${ }^{2}$ Department of Civil Engineering, State Polytechnic of Kupang, Kupang, East Nusa Tenggara 85141, Indonesia
}

Correspondence should be addressed to Melchior Bria; melchibria@yahoo.co.id

Received 11 February 2021; Revised 22 October 2021; Accepted 2 November 2021; Published 19 November 2021

Academic Editor: Jaeyoung Lee

Copyright (C) 2021 Ludfi Djakfar et al. This is an open access article distributed under the Creative Commons Attribution License, which permits unrestricted use, distribution, and reproduction in any medium, provided the original work is properly cited.

\begin{abstract}
Although transport mode choice in commuting from home to work has been studied extensively, no prior research has investigated mode choice as an emotional response to external stimuli using the stimulus-organism-response (SOR) model. Therefore, this study applies the SOR model to explore commuters' transport mode choice behaviour. The stimulus variables include trip characteristics, transport infrastructure and services, environment, and work characteristics; the organism variable includes the travel experience and attitude of the individual; and the response variables include use of public transport, private transport, and e-hailing. Data were collected using a questionnaire survey of 500 formal-sector workers in Jakarta; 430 respondents provided valid responses for analysis. The survey data were analysed using partial least squares-structural equation modelling. The results showed that the stimulus variables, namely, trip characteristics, transport infrastructure, environment, and work characteristics, had indirect effects on the choice of e-hailing through organism factors (travel experience and attitude). Also, the environment and work characteristic variables had an indirect effect on the choice of private transport through organism factors. Stimulus variables had no indirect effects on public transport usage. When travel experience was the stimulus variable, the indirect effect on public transport usage through attitude as the organism variable was significant. The response to the use of transport modes showed dynamic behaviour, depending on the provided stimulus and organism. These findings can be beneficial for establishing a more comprehensive strategy that includes the provision of infrastructure, improvement of transit service, the built environment, and employers' policies to realise a sustainable commuting trip.
\end{abstract}

\section{Introduction}

The daily routine of commuting from home to work is often found among urban residents who choose between active (walking and cycling) and passive (bus, train, car, and motorcycle) transport modes [1]. In addition to public transport, many cities in the world now have e-hailing services, which use cars, motorbikes, and other vehicles. The variety of transport mode choices is found to be a threat and challenge to efforts to increase the preferences for public transport. One challenge is the increasing use of private transport, which causes congestion as well as air and noise pollution in urban areas. According to Yang et al. [2], high use of private transport was attributable to increasing vehicular ownership and inadequate public transport services. Therefore, efforts to increase the use of public transport for routine trips is one method of maintaining sustainable transport services within a city [3]. However, e-hailing services offering convenience, timeliness, and affordable fares are more attractive to users than public transport $[4,5]$.

Previously, transport studies have been using various behavioural theories, including the theory of planned behaviour $[6,7]$, theory of reasoned action $[8,9]$, and discrete choice modelling based on macroeconomic theory [10] to explore the factors affecting individuals' behaviours. Shaaban and Maher [11] used the theory of planned behaviour to explain commuters' behaviour based on subjective assessments and behavioural control of intentions towards using public transport. However, the theory of planned behaviour does not provide the firmness that a certain intention affects the formation of mode choice behaviour [7]. Meanwhile, analysis based on this theoretical approach cannot provide a 
firmness that subjective intentions and judgments will stimulate the emergence of a decision on whether or not to select a specific transport mode. Besides subjective attitudes and norms, the decision-making process on transport mode choice is further influenced by various other factors.

Several previous studies have employed demographic factors such as age, income, number of family members, and vehicle ownership to explain mode choice behaviour [12-14]. Furthermore, studies using travel attributes such as travel time, distance, cost of waiting and transfer between modes, and time of day also have been conducted by experts to explain the factors that influence mode choice behaviour [14-16]. Moreover, network characteristics such as the availability of road networks, modes of transport, and accessibility also affect this choice [17].

Cheng et al. [18] used SEM analysis to explore the travel behaviour of commuters and its relationship with sociodemographics, accessibility, and activity systems in a study from Nanjing, China. Meanwhile, Plavara Alex et al. [19] found that SEM analysis could explain the relationship between attitude, lifestyle, and transport mode reliability as predictors of transport mode choice. They emphasised the effectiveness of the inclusion of latent variables to predict mode choice behaviour, compared to sociodemographics alone.

However, previous studies did not specifically examine the decision to choose a particular mode as the result of an interrelated process between external stimuli and an individual's travel experiences and attitudes. For example, the provision of adequate infrastructures is a strategy that should be implemented, when most commuters are found to use public transport. This is because the infrastructural implementations are expected to stimulate interest in public transport services, that is, operate as a stimulus. Furthermore, even when these infrastructures are made available, the choice of public transport may depend on individual commuters' specific experiences or attitudes, representing the influence of emotion. It is, therefore, necessary to study how stimuli interact with emotion to produce a certain behavioural response in terms of commuters' transport mode choice.

For this purpose, this study utilises the stimulusorganism-response (SOR) model, which was developed by Mehrabian and Russell [20]. The SOR model is often used to study consumer behaviours in terms of selecting or using specific products. As Figure 1 illustrates, the SOR model explains how the environment provides certain stimuli that influence feelings, leading in turn to a response in the form of approaching or avoiding [21]. Based on the SOR model, the organism mediates the relationship between the stimulus and response (independent and dependent variables) [22], as shown in Figure 1.

Studies using the SOR model to analyse the selection behaviour of transport modes are still rarely performed. Several studies related to transport and SOR model application are still relatively general and have not specifically discussed mode choices. Ngah et al. [23] determined the factors that affected the willingness to pay for halal transportation by using the SOR model. Othman et al. [24] used
SOR to analyse brand choice in air transport, while Dzandu et al. [25] utilised the model in understanding the adoption of autonomous vehicles.

This study uses the SOR model to investigate the transport mode choice behaviour of commuters. This novel approach will enrich the understanding of travel behaviour, complementing the various models used in previous studies of transport mode choice. Furthermore, this study evaluates the extent to which particular factors can become stimuli and organism variables for use of public transport, private transport, and e-hailing.

\section{Hypothesis Development}

According to the study by Mehrabian and Russell [26], the SOR model stimulus conceptually contained three dimensions, namely, evaluation, activity, and potential. Meanwhile, the characteristics of the organism consisted of pleasure, arousal, and dominance, and the features of response contained approach or avoidance. Jacoby [27] argued that stimulus in the SOR model is an external factor that influences individuals, excluding sociocultural indicators. According to the study, the organism elements are comprised of psychology, experience, knowledge, perception, and cognition, while the response elements may include verbal, nonverbal, and behavioural.

Referring to the definition of the SOR model above and considering sustainable urban transport, the provision of stimulus needs to be directed at efforts to increase the use of public transport. Several previous studies have revealed the importance of providing adequate accessibility to encourage commuters to use public transport [17, 18, 28]. A study of work trips in Lisbon, Portugal, indicates that accessibility needs to be supported by a good connectivity system to encourage the use of public transport [29]. Adequate accessibility needs adequate transport infrastructure such as road networks, terminals, or stations for good connectivity [30]. A study conducted by Parthasarathi and Levinson [31] showed that the provision of infrastructure is part of the spatial arrangement of an area and has a significant effect on travel.

However, the sensitivity of mode choice behaviour is also often influenced by travel characteristics [32]. In a study conducted in Valencia, Spain, Arroyo et al. [33] found that travel with single characteristics (solo) tends to be easier to adapt to sustainable transport programmes. A study conducted by Huang [17] on employees who made commuting trips in Milwaukee, United States, showed that accessibility was related to travel attributes such as commuting time. Studies on the effect of travel characteristics have also been carried out in Jakarta, Indonesia, where costs, transfer times, and waiting times affected the choice of transport modes [34].

However, it should also be realised that transport infrastructure is built in a built environment. This needs to be a concern because, in a dense and diverse environment, adequate transport infrastructure is needed to encourage the use of public transport $[28,35]$. A study in the Baltimore metropolitan area, United States, indicated that 


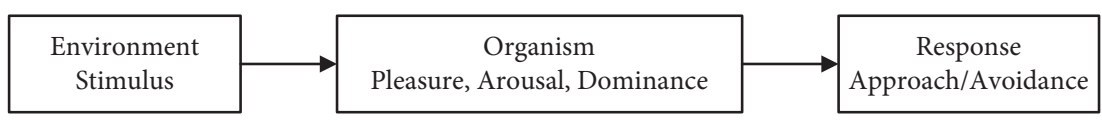

FIGURE 1: Framework of the SOR model [20].

environmental density tends to increase people's use of public transport [36]. However, a study in Rome, Italy, found that when travelling for work, environmental density did not affect the choice of using sustainable transport modes [37].

Furthermore, a study carried out by Athira et al. [14] in Calicut city, India, found that occupational factors had a significant influence on travel modes based on the value of time (VoT). Therefore, work-related factors such as duration and start time can also be identified as stimuli for commuting trips and part of employers' policies [38, 39]. In a study carried out in Belgium, Ermans et al. [40] stated that congestion, pollution, and other problems in urban transport are some of the problems in the transport system also in addition to employer policies, which can be in the form of reward or punishment. Therefore, there needs to be a balance between reward and punishment in work. According to Batista Ferrer et al. [41], policies such as providing incentives for employees that use public transport tend to be more acceptable than eliminating parking at the office.

Next, the concept of the organism in commuting can be interpreted as an expression of pleasure, satisfaction, experience, and attitude towards the use of certain modes of transport. Heinen and Bohte [42] in a study carried out in the Netherlands found the use of public transport along with bicycles healthy, enjoyable, and capable of reducing carbon dioxide emissions in the air. Chatterjee et al. [43] stated that it is necessary to have a more comprehensive understanding of the travel experience with the intention of satisfying commuters while travelling. Meeting the safety standards, comfortable and safe transport services provide a pleasant experience related to mode choice behaviour. Chen and $\mathrm{Li}$ [44] utilised data in Chengdu city, China, and found that convenience, security, and transport mode services had a strong correlation with the use of public transport. In addition, several studies show that convenience, reliability, and security are factors that influence the decision to choose e-hailing services [45-47].

Considering that in urban areas, sustainable transport needs to be encouraged $[48,49]$, this study considers trip characteristics, transport infrastructure and services, environment, and work characteristics as stimulus factors that influence the response to transport modes through travel experience and attitude factors as organisms. In this study, response is a variable that describes the public transport, private transport, and e-hailing usages.

2.1. Trip Characteristics. The transport mode choice involved several factors that were related to trip characteristics, such as travel attributes. These attributes included travel distance, time, and cost $[14,31]$, which depended on the origin of movement and destination. A study in Shanghai,
China, showed that the choice of commuters who travel daily on public transport is influenced by travel time and distance to stations or buses [50]. Based on a working trip, the travel characteristics were related to the time of leaving for work and time of returning home from work. One study in New York related to commuting showed that the time to leave for work is one of the factors that influence the mode of transport used by employees [16]. Furthermore, according to Deka [51], based on travel data from the US National Household Travel Survey, parents often stop by to take their children to school when they travel to work [51]. Characteristics such as stopping to do other activities after work before returning home are often encountered [52]. Therefore, the following hypotheses are proposed:

(i) Hypothesis 1 (H1). Trip characteristics have a significant indirect effect on the choice of public transport through travel experience and attitude

(ii) Hypothesis 2 (H2). Trip characteristics have a significant indirect effect on the choice of private transport through travel experience and attitude

(iii) Hypothesis 3 (H3). Trip characteristics have a significant indirect effect on the choice of e-hailing through travel experience and attitude

2.2. Infrastructure Transport and Services. The provision of transport infrastructure is an important element in the urban transport system [53]. Transport infrastructure consists of two categories, namely, hard infrastructure (highways, rail networks, terminals, stations, transport vehicles, subways, traffic lights and street lights, airports, bridges, and others) and soft infrastructure (information technology, regulation, financial system, and others) [54]. The study conducted by Parthasarathi and Levinson [31] in Minneapolis-St. Paul, United States, showed that the structure of the road network is related to travel behaviour. A study conducted in Rome, Italy, also showed that the availability of transport infrastructure such as a road network is related to mode choice [37]. The availability of the road network provides high accessibility for travel and good intermodal connectivity provides opportunities for the use of public transport [29]. Furthermore, a study of transport policy in Hanoi, Vietnam, showed that the provision of facilities for public transport and the improvement of its services have an impact on reducing trips using private vehicles [55]. Meanwhile, a study by Irfan et al. [56] in Rawalpindi, Pakistan, showed that the provision of infrastructure and the improvement of public transport services had no impact on reducing car use. Referring to the explanation above, the following hypotheses are proposed:

(i) Hypothesis 4 (H4). Infrastructure transport and services have a significant indirect effect on the 
choice of public transport through travel experience and attitude

(ii) Hypothesis 5 (H5). Infrastructure transport and services have a significant indirect effect on the choice of private transport through travel experience and attitude

(iii) Hypothesis 6 (H6). Infrastructure transport and services have a significant indirect effect on the choice of e-hailing through travel experience and attitude

2.3. Environment. The definition of environmental factors in this study is an urban area that is built including various transport infrastructures that exist in it as well as its natural environment. This built environment is generally designed and built based on certain land-use patterns, which may or may not represent a diverse environment [57]. The pattern of land use that demands separation between residential and office areas causes trips to occur from home to office [41]. However, the characteristics of the trip from home to the office can also affect the choice of residential location $[58,59]$. A study conducted by Tran et al. [35] in Hanoi, Vietnam, showed that variations in land use require a variety of choices of transport modes. Thus, it is necessary to regulate the environment by bringing the house closer to the office location. A study in Mexico showed that in a dense office environment and close to residential locations, the tendency to use cars is reduced if public transport is available [60]. Then, related to natural conditions, the weather factor is a stimulus for the use of certain modes of transport [61]. Therefore, the following hypotheses are proposed:

(i) Hypothesis 7 (H7). Environments have a significant indirect effect on the choice of public transport through travel experience and attitude

(ii) Hypothesis 8 (H8). Environments have a significant indirect effect on the choice of private transport through travel experience and attitude

(iii) Hypothesis 9 (H9). Environments have a significant indirect effect on the choice of e-hailing through travel experience and attitude

2.4. Work Characteristics. Given this study's focus on the choice of transport mode between home and work, job characteristics were considered likely to influence mode choice. A literature study conducted by Alcover and Topa [62] stated that job characteristics are generally related to personal and organisational with assignments comprising aspects of time, decision making (policy), and work methods. In the context of this study, the job characteristics can be in the form of working time (flexible or not), duration, and work method (outdoor or indoor) and can be in the form of reward and punishment. A study conducted by Ton et al. [38] in the Netherlands found that in commuting trips, work conditions play an important role in influencing employee behaviour in using transport modes. More specifically, the results of the analysis of a study conducted in
Thiruvananthapuram, India, showed that as the duration of work increases, the use of public transport decreases [19]. Meanwhile, a study done by Cheng et al. [18] in Nanjing, China, found that setting the right work duration can increase the use of public transport. Another study conducted by Batista Ferrer et al. [41] in the south west of England and South Wales proposed that incentives as a reward for employees who use public transport cannot be implemented to increase employee preferences for public transport. With these previous studies in mind, the following hypotheses are proposed:

(i) Hypothesis 10 (H10). Work characteristics have a significant indirect effect on the choice of public transport through travel experience and attitude

(ii) Hypothesis 11 (H11). Work characteristics have a significant indirect effect on the choice of private transport through travel experience and attitude

(iii) Hypothesis 12 (H12). Work characteristics have a significant indirect effect on the choice of e-hailing through travel experience and attitude

2.5. Travel Experience and Attitude. According to AbabioDonkor et al. [63], in Scotland, United Kingdom, sentiment towards and experience of using public transport had a significant influence on transport mode choice. This finding indicates that the behaviour of selecting a transport mode is a statement of attitude, based on an individual's experience of and specific perspective on travel. Travel experience is a subjective element measured through indicators of specific standards, such as reliability, comfort, convenience, and safety [64]. Furthermore, this experience can be pleasant or unpleasant; in some cases, it might even be traumatising. As modes of transport vary in the extent of their impact on pollution and in fuel economy, it is also necessary to consider the extent to which people consider these issues. Based on a social perspective, the behaviour of using transport modes in travelling within the city had similarly become a lifestyle [65]. As commuting is inherently related to work, attitudes towards work (such as job satisfaction) should also be considered. Accordingly, travel experience and attitude were included as organism variables in the SOR model. The following hypotheses are presented in light of these findings:

(i) Hypothesis 13 (H13). Travel experience has a significant indirect effect on the choice of public transport through attitude

(ii) Hypothesis 14 (H14). Travel experience has a significant indirect effect on the choice of private transport through attitude

(iii) Hypothesis 15 (H15). Travel experience has a significant indirect effect on the choice of e-hailing through attitude

Figure 2 visualises the hypothesised relationship between variables based on the SOR concept. In this hypothetical model, the indirect effect has two meanings. Firstly, there were two indirect relationships between stimulus and response variables, through one organism factor. These included 


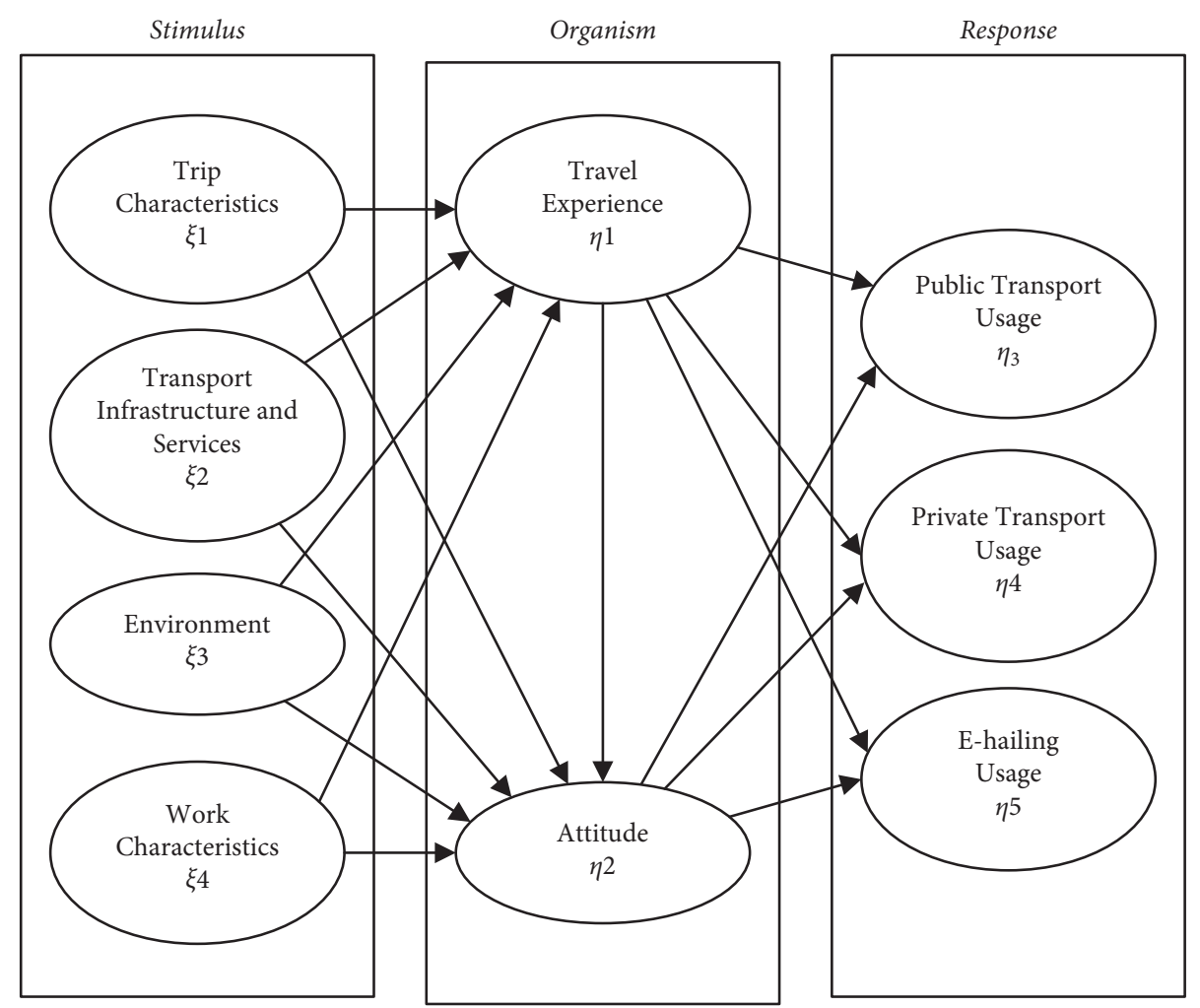

Figure 2: Hypothetical model based on the concept of SOR.

stimulus-organism $\eta_{1^{-}}$and $\eta_{2}$-responses. Each of the two models contained only one mediation, and they are also known as two-segment relationships. Secondly, there were indirect relationships between the stimulus and response variables, through the organism factors of $\eta_{1}$ and $\eta_{2}$. Based on being a three-segment relationship, $\eta_{1}$ was assumed to have an effect on $\eta_{2}$ (stimulus-organism $\eta_{1}$-organism $\eta_{2}$-response), in order to have two mediating variables.

\section{Methods}

3.1. Data Collection. The data for this case study were obtained from a survey conducted in Jakarta, Indonesia. This city has a complex urban transport system including both infrastructural and integrated public services, such as Transjakarta BRT and Jakarta MRT. It is also a centre of economic activity due to the growth and development of the formal sector. However, like many cities in the world, Jakarta has experienced transport problems such as congestion and both air and noise pollution, attributable to the high use of private transport in the city. Therefore, global issues related to sustainable transport are relevant to this study's focal location.

The first stage in data collection was to design a questionnaire consisting of two parts. The first part of the questionnaire contains questions about the characteristics of the respondents consisting of gender, age, educational background, occupation, working period, income, the number of members in the family, and vehicle ownership. The second part of the questionnaire is used to measure stimulus, organism, and response variables.

The second stage was distributing questionnaires to respondents to obtain research data. The study's respondents were all workers in the formal sector who live and work in Jakarta. The formal sector includes government, private, and nonprofit organisations, as well as other official institutions. The questionnaire was distributed to respondents by two survey teams. Adopting the methods used by Washington et al. [66], sampling was carried out by using simple random technique, in order to obtain travel behaviour data. Accordingly, respondents were randomly selected from the population, with no focus on work or location. Furthermore, respondents completed the questionnaire through two methods, namely, interview and direct contact techniques.

The minimum number of samples was determined by [67]

$$
N=\left(\frac{Z_{\mathrm{CL}}+Z_{\mathrm{FP}}}{|\widehat{\beta O}|}\right)^{2} .
$$

Using this formula, 286 respondents were obtained, based on the assumptions that a false positive level of $10 \%$ aimed for a confidence of $95 \%$, as the total values of trust, error percentage, and estimation (ZCL, ZFP, and $(|\widehat{\beta o}|))$ were $1.6449,1.2816$, and 0.0215 , respectively [67]. Based on the perceptions by Hair et al. [68], we concluded that PLSSEM had the potential to produce good analysis with a larger sample size. Accordingly, the questionnaire was distributed to 500 respondents. Ultimately, 430 respondents provided 
completed surveys that were suitable for analysis; the other 70 surveys were either incomplete or not returned. The characteristics of the respondents involved in this study are presented in Table 1.

The composition of respondents by gender showed that the majority of respondents were male (71.4\%). Referring to the age of the respondents, the majority were between 20 and 40 years old (78.14\%), and their educational level was mostly undergraduates $(52.79 \%)$ and high school graduates at 42.09\%. Most respondents are private employees $(68.60 \%)$, followed by civil servants and entrepreneurs with almost the same percentage. Meanwhile, the majority of respondents $(88.60 \%)$ had an average income of up to IDR $10,000,000$ in one month, while the percentage of respondents with income above that level was $11.4 \%$. Around $49.07 \%$ of respondents had families between 3 and 4 people and $37.44 \%$ had 1-2 people in the household, while the rest had families with above 4 people (13.49\%). Lastly, most of the respondents own 1 vehicle $(67.67 \%)$ and 2 vehicles at $20.7 \%$, while those who do not own one and those who own more than 3 made up a small percentage of respondents.

3.2. Analytical Methodology. This study aims to obtain an overview of urban commuters' mode choice between public transport, private transport, and e-hailing using the SOR model. The method utilised to test the SOR model hypothesis in Figure 1 was partial least squares-structural equation modelling (PLS-SEM). Studies conducted by $\mathrm{Li}$ [21], Hew et al. [69], and Kim et al. [70] showed that PLSSEM is able to explain the application of the SOR model in describing individual behaviour. Furthermore, PLS-SEM in was used considering that this analysis does not require the assumption of normality of the data and it also estimates complex models [68]. This is because PLS-SEM has an asymptotic distribution-free (ADF) property, which is a measurement of variable estimation without the assumption of a normal distribution [71]. Referring to the nature of ADF, the data in PLS-SEM can be in the form of the nominal, ordinal, interval, and ratio data [72], which corresponds to the data type in this study.

Consistent with the nature of the ADF, the data to measure the construct latent trip characteristics were in nominal terms for indicators $X_{1}$ to $X_{5}$. A scale of 1-10 was further used to measure $X_{6}$ and $X_{7}$ on the trip characteristics variable. This was also used to measure the indicators of transport infrastructure and services $\left(X_{8}\right.$ to $\left.X_{14}\right)$, environment $\left(X_{15}\right.$ to $\left.X_{19}\right)$, and work characteristics $\left(X_{20}\right.$ to $\left.X_{25}\right)$; travel experience $\left(Y_{1}-Y_{5}\right)$, attitude $\left(Y_{6}-Y_{9}\right)$, and transport modes $\left(Y_{10}-Y_{15}\right)$. An interval scale was also used in the work characteristics variable, measurement indicators $X_{26}$ and $X_{27}$. The anchor points of the scale were 1 ("strongly disagree") and 10 ("strongly agree"), indicating each respondent's agreement with the statements in the questionnaire.

Analysis in PLS-SEM included outer and structural (inner) models. First, the outer model was designed to determine the relationship between the indicators contained in the variables, which were reflective or formative. The main characteristic of a reflective model is obtained when the construct causes the indicator to change. Conversely, the formative feature is obtained when the indicator affects the construct [68]. In this study, the variables with formative indicators were trip and work characteristics, environment, as well as public transport, private transport, and e-hailing usages. Meanwhile, those with reflective factors were transport infrastructure and services, as well as trip experience and attitude. Based on the above description of the construction of the SOR model, these indicators were developed as shown in Table 2. The relationships between variables and indicators are expressed using loading factors $\left(\lambda_{x i}\right)$.

Second, the structural model represents the relationship pattern between the constructs [68] and is based on the model hypothesis (Figure 2). The exogenous constructs (denoted by $\xi$ ) are stimulus factors, while endogenous constructs (denoted by $\eta$ ) are organism factors and responses. However, when analysing the relationship between organism and response variables, the former was categorised as exogenous. Path coefficients were used to evaluate the relationship between variables. As shown in Table 2, $\gamma$ was the path coefficient for the relationship between exogenous and endogenous variables, while $\beta$ was the coefficient for the relationship between the endogenous variables.

Based on the outer and structural models, the general forms of the regression equation are mathematically written as follows:

$$
\begin{aligned}
& \eta_{1}=\gamma_{1} \xi_{1}+\gamma_{3} \xi_{2}+\gamma_{5} \xi_{3}+\gamma_{7} \xi_{4}+\zeta_{i}, \\
& \eta_{2}=\beta_{1} \eta_{1}+\gamma_{2} \xi_{1}+\gamma_{4} \xi_{2}+\gamma_{6} \xi_{3}+\gamma_{8} \xi_{4}+\zeta_{2}, \\
& \eta_{3}=\beta_{2} \eta_{1}+\beta_{5} \eta_{2}+\zeta_{3}, \\
& \eta_{4}=\beta_{3} \eta_{1}+\beta_{6} \eta_{2}+\zeta_{4}, \\
& \eta_{5}=\beta_{4} \eta_{1}+\beta_{7} \eta_{2}+\zeta_{5} .
\end{aligned}
$$

According to the relationship between variables and indicators, the general form of the equation is

$$
\begin{array}{ll}
x_{i}=\lambda_{x i} \xi+\delta_{x i}, & \text { for exogenous variables, } \\
y_{i}=\lambda_{y i} \eta+\varepsilon_{y i}, & \text { for endogenous variables, }
\end{array}
$$

where $\eta=$ endogenous latent variable, $\xi=$ exogenous latent variable, $\lambda_{x}=$ exogenous variable loadings, $\lambda_{y}=$ endogenous variable loadings, $\beta=$ path coefficient of endogenous variable to endogenous variable, $\gamma=$ path coefficient of exogenous variable to endogenous variable, $\zeta=$ model error, $\delta=$ measurement error of exogenous variables, and $\varepsilon=$ measurement error of endogenous variables.

In this study, it was essential to analyse indirect relationships in the model as part of the structural evaluation. The purpose of this indirect relationship test is to determine the value of the indirect effect on the two-segment and threesegment relationship [73]. According to a two-segment relationship, the total value of the indirect effect was calculated based on the path coefficients $(\gamma$ and $\beta)$. For example, in the association of $\xi_{1}$ and $\eta_{3}$, there were two indirect 2segment $\left(\xi_{1}-\eta_{1}-\eta_{3}\right.$ and $\left.\xi_{1}-\eta_{1}-\eta_{3}\right)$ and one 3-segment $\left(\xi_{1}-\eta_{1}-\eta_{2}-\eta_{3}\right)$ relationships. Therefore, the total indirect effects were $\gamma_{1} \beta_{2}+\gamma_{2} \beta_{5}$ and $\gamma_{1} \beta_{1} \beta_{5}$ for two- and three- 
TABLE 1: Detailed description of respondents' characteristics.

\begin{tabular}{|c|c|c|c|}
\hline Characteristics of respondents & Details & Frequency & Percentage \\
\hline \multirow{2}{*}{ Gender } & Male & 307 & 71.20 \\
\hline & Female & 124 & 28.80 \\
\hline \multirow{4}{*}{ Age } & 20-30 years old & 195 & 45.35 \\
\hline & $>30-40$ years old & 141 & 32.79 \\
\hline & $>40-50$ years old & 79 & 18.37 \\
\hline & $>50$ years old & 15 & 3.49 \\
\hline \multirow{4}{*}{ Education } & Middle school & 4.00 & 0.93 \\
\hline & High school & 181.00 & 42.09 \\
\hline & Undergraduate & 227.00 & 52.79 \\
\hline & Postgraduate & 18.00 & 4.19 \\
\hline \multirow{4}{*}{ Occupation } & Civil servants & 68 & 15.81 \\
\hline & Private employees & 295 & 68.60 \\
\hline & Entrepreneur & 65 & 15.12 \\
\hline & Others & 2 & 0.47 \\
\hline \multirow{4}{*}{ Working period } & $<5$ years & 216 & 50.23 \\
\hline & $5-10$ years & 117 & 27.21 \\
\hline & $10-20$ years & 74 & 17.21 \\
\hline & $>20$ years & 23 & 5.35 \\
\hline \multirow{5}{*}{ Income } & $<$ IDR $5,000,000$ & 198 & 46.05 \\
\hline & IDR $5,000,000-10,000,000$ & 183 & 42.56 \\
\hline & $>$ IDR10,000,000-15,000,000 & 29 & 6.74 \\
\hline & $>$ IDR $15,000,000-20,000,000$ & 14 & 3.26 \\
\hline & $>$ IDR 20000000 & 6 & 1.40 \\
\hline \multirow{4}{*}{ Number of family members } & 1-2 people & 161 & 37.44 \\
\hline & 3-4 people & 211 & 49.07 \\
\hline & 5-6 people & 54 & 12.56 \\
\hline & $>6$ people & 4 & 0.93 \\
\hline \multirow{5}{*}{ Vehicle ownership } & None & 27 & 6.28 \\
\hline & 1 vehicle & 291 & 67.67 \\
\hline & 2 vehicles & 89 & 20.70 \\
\hline & 3 vehicles & 18 & 4.19 \\
\hline & $>3$ vehicles & 5 & 1.16 \\
\hline
\end{tabular}

TABLE 2: Description of measurement items in the model and indicators to measure the latent construct.

\begin{tabular}{|c|c|c|c|}
\hline $\begin{array}{l}\text { Constructs and their } \\
\text { interrelationships }\end{array}$ & $\begin{array}{c}\text { Path } \\
\text { coefficients }\end{array}$ & $\begin{array}{l}\text { Loading factors } \\
\left(\lambda_{x i} ; \lambda_{y i}\right)\end{array}$ & Indicator \\
\hline $\begin{array}{l}\text { Trip characteristics } \\
\left(\xi_{1}\right) \\
\xi_{1}-\eta_{1} \\
\xi_{1}-\eta_{2}\end{array}$ & $\begin{array}{l}\gamma_{1} \\
\gamma_{2}\end{array}$ & $\begin{array}{l}\lambda_{x 1} \\
\lambda_{x 2} \\
\lambda_{x 3} \\
\lambda_{x 4} \\
\lambda_{x 5} \\
\lambda_{x 6} \\
\lambda_{x 7}\end{array}$ & $\begin{array}{c}X_{1} \text { - the average travel cost for one trip to work } \\
X_{2} \text {-the average travel time for one trip to work } \\
X_{3} \text {-the average distance from home to work } \\
X_{4} \text {-the time of leaving to work } \\
X_{5} \text {-the time of coming home from work } \\
X_{6} \text { - I stop somewhere else before going to work } \\
X_{7} \text {-I perform other activities after work, before returning home }\end{array}$ \\
\hline $\begin{array}{l}\text { Transport infrastructure and } \\
\text { services }\left(\xi_{2}\right) \\
\xi_{2}-\eta_{1} \\
\xi_{2}-\eta_{2}\end{array}$ & $\begin{array}{l}\gamma_{1} \\
\gamma_{2}\end{array}$ & $\begin{array}{l}\lambda_{x 8} \\
\lambda_{x 9} \\
\lambda_{x 10} \\
\lambda_{x 11} \\
\lambda_{x 12} \\
\lambda_{x 13} \\
\lambda_{x 14}\end{array}$ & $\begin{array}{l}X_{8} \text { - I believe the current availability of transport infrastructure is } \\
\text { adequate } \\
X_{9} \text { - I believe the availability of parking spaces at work is sufficient } \\
X_{10} \text {-Vehicle parking at my workplace is available at affordable prices } \\
X_{11} \text {-in my opinion, connectivity between modes in the transport system } \\
\text { is presently sufficient } \\
X_{12} \text {-the present public transport load capacity service is adequate } \\
X_{13} \text {-information technology applications in the transport system make it } \\
\text { easier for me to travel to work from home and vice versa } \\
X_{14} \text { - I believe that the provision of facilities to ensure the accessibility of } \\
\text { public transport is adequate }\end{array}$ \\
\hline
\end{tabular}


TABLE 2: Continued.

\begin{tabular}{|c|c|c|c|}
\hline $\begin{array}{l}\text { Constructs and their } \\
\text { interrelationships }\end{array}$ & $\begin{array}{l}\text { Path } \\
\text { coefficients }\end{array}$ & $\begin{array}{l}\text { Loading factors } \\
\left(\lambda_{x i} ; \lambda_{y i}\right)\end{array}$ & Indicator \\
\hline $\begin{array}{l}\text { Environment }\left(\xi_{3}\right) \\
\xi_{3}-\eta_{1} \\
\xi_{3}-\eta_{2}\end{array}$ & $\begin{array}{l}\gamma_{1} \\
\gamma_{2}\end{array}$ & $\begin{array}{l}\lambda_{x 15} \\
\lambda_{x 16} \\
\lambda_{x 17} \\
\lambda_{x 18} \\
\lambda_{x 19}\end{array}$ & $\begin{array}{c}X_{15} \text {-my workplace is accessible using various modes of transport } \\
X_{16} \text { - where I live is accessible using various modes of transport } \\
X_{17} \text {-the neighbourhood where I live is a high-density area } \\
X_{18} \text {-the road conditions around where I live are good and stable } \\
X_{19} \text { - I consider the weather before using certain modes of transport }\end{array}$ \\
\hline $\begin{array}{l}\text { Work characteristics }\left(\xi_{4}\right) \\
\xi_{4}-\eta_{1} \\
\xi_{4}-\eta_{2}\end{array}$ & $\begin{array}{l}\gamma_{1} \\
\gamma_{2}\end{array}$ & $\begin{array}{l}\lambda_{x 20} \\
\lambda_{x 21} \\
\lambda_{x 22} \\
\lambda_{x 23} \\
\lambda_{x 24} \\
\lambda_{x 25} \\
\lambda_{x 26} \\
\lambda_{x 27}\end{array}$ & $\begin{array}{c}X_{20}-\text { my workplace has flexible hours for starting and finishing work } \\
X_{21} \text { - I always work daily, based on normal work duration (according to } \\
\text { the regulations of workplace) } \\
X_{22} \text { - when I work, I am often indoors } \\
X_{23} \text {-I receive a monetary incentive to use public transport } \\
X_{24} \text { - where I work, I receive a disciplinary sanction when arriving late } \\
X_{25} \text { - I often travel during working hours } \\
X_{26} \text {-the time of starting work } \\
X_{27} \text {-the time of finishing work }\end{array}$ \\
\hline $\begin{array}{l}\text { Travel experience }\left(\eta_{1}\right) \\
\eta_{1}-\eta_{2} \\
\eta_{1}-\eta_{3} \\
\eta_{1}-\eta_{4} \\
\eta_{1}-\eta_{5}\end{array}$ & $\begin{array}{l}\beta_{1} \\
\beta_{2} \\
\beta_{3} \\
\beta_{4}\end{array}$ & $\begin{array}{l}\lambda_{y 1} \\
\lambda_{y 2} \\
\lambda_{y 3} \\
\lambda_{y 4} \\
\lambda_{y 5}\end{array}$ & $\begin{array}{c}Y_{1} \text { - reliability, in terms of punctuality, of my regular transport to work is } \\
\text { very important to me } \\
Y_{2} \text { - I need a high standard of security in my regular transport to work } \\
Y_{3} \text {-I need high safety standards in my regular transport to work } \\
Y_{4} \text { - I need a high standard of comfort in my regular transport between } \\
\text { home and work } \\
Y_{5} \text {-I have a feeling of trauma about a certain transport mode }\end{array}$ \\
\hline $\begin{array}{l}\text { Attitude }\left(\eta_{2}\right) \\
\eta_{2}-\eta_{3} \\
\eta_{2}-\eta_{4} \\
\eta_{2}-\eta_{5}\end{array}$ & $\begin{array}{l}\beta_{5} \\
\beta_{6} \\
\beta_{7}\end{array}$ & $\begin{array}{l}\lambda_{y 6} \\
\lambda_{y 7} \\
\lambda_{y 8} \\
\lambda_{y 9} \\
\end{array}$ & $\begin{array}{c}Y_{6}-\mathrm{I} \text { think that energy-saving issues are very important } \\
Y_{7} \text {-I consider environmental pollution on regular trips between home } \\
\text { and work } \\
Y_{8} \text {-regular trips from home to work and vice versa by using specific } \\
\text { transport modes are part of my daily life } \\
Y_{9}-\mathrm{I} \text { am satisfied with my present job }\end{array}$ \\
\hline $\begin{array}{l}\text { Public transport } \\
\text { usage }\left(\eta_{3}\right)\end{array}$ & & $\begin{array}{l}\lambda_{y 10} \\
\lambda_{y 11}\end{array}$ & $\begin{array}{c}Y_{10} \text {-I use Transjakarta BRT to commute to work } \\
Y_{11} \text {-I use Jakarta MRT to commute to work }\end{array}$ \\
\hline $\begin{array}{l}\text { Private transport } \\
\text { usage }\left(\eta_{4}\right)\end{array}$ & & $\begin{array}{l}\lambda_{y 12} \\
\lambda_{y 13}\end{array}$ & $\begin{array}{c}Y_{12}-\mathrm{I} \text { use the car to commute to work } \\
Y_{13}-\mathrm{I} \text { use a motorbike to commute to work }\end{array}$ \\
\hline $\begin{array}{l}\text { e-hailing } \\
\text { usage }\left(\eta_{5}\right)\end{array}$ & & $\begin{array}{l}\lambda_{y 14} \\
\lambda_{y 15}\end{array}$ & $\begin{array}{c}Y_{14} \text {-I use an e-cab hailing service to commute to work } \\
Y_{15} \text {-I use an e-motorbike hailing service to commute to work }\end{array}$ \\
\hline
\end{tabular}

segment relationships, where $\gamma_{1}, \gamma_{2}, \beta_{2}$, and $\beta_{5}$ are the path coefficients, as described in Table 2 . The total indirect effects were similarly calculated for other variables in the model. This further indicated that the greater values of indirect effects lead to stronger significant level of variable relationships, and vice versa. The analysis of the PLS-SEM model used the free version of WarpPLS 6.0 software, which can be downloaded from the official WarpPLS website [74].

The model was evaluated in two stages:

(i) First, the evaluation of the measurement model included testing the validity and reliability of the reflective and formative indicator models. The reflective model was evaluated by tests of validity (convergent and discriminant) and reliability (internal and indicator) [68]. The formative model was evaluated by testing collinearity (variance inflation factors (VIFs)) and indicator weights [73].

(ii) Second, the structural model was assessed in terms of predictive relevance $\left(R\right.$-squared $\left(R^{2}\right)$ and $Q$-squared $\left(Q^{2}\right)$ coefficients), collinearity (VIFs), goodness of fit (GoF), level significance, path coefficients, and indirect effects [73].

\section{Results}

4.1. Measurement Model. We first tested convergent and discriminant validity. Convergent validity is inferred when the loading factor, $p$ value, and average variance extracted (AVE) of the reflective construct are $>0.5,<0.05$, and $>0.5$, respectively [68]. Table 3 shows that the loading factors of transport infrastructure and services and of travel experience were $<0.5$, as observed on indicators $X_{10}, X_{14}$, and $Y_{5}$. Also, the loading factors of $Y_{2}$ and $Y_{3}$ were very high $(>0.90)$, with the values still allowed due to their being less than 0.95 . Loading factors $>0.95$ caused an increase in the correlation between indicators and also the possible occurrence of an unexpected response [68]. Accordingly, these indicators' loading factors were not considered problematic. Table 3 also shows that the AVE values of travel experience and attitude were greater than 0.5 , thus meeting this requirement for convergent validity. However, the AVE value of the transport infrastructure and services variable was $<0.5$, and so it did not meet the required standard.

Furthermore, the discriminant validity test should be greater than the AVE root of other latent variables [73], in accordance with the Fornell-Larcker criteria [75]. Table 4 
TABLE 3: Results of convergent validity and reliability tests.

\begin{tabular}{|c|c|c|c|c|c|c|}
\hline Variable & Indicator & Loadings & $p$ value & AVE & Composite reliability & Cronbach's alpha \\
\hline \multirow{7}{*}{ Transport infrastructure and services $\xi_{2}$} & $X_{8}$ & 0.612 & $<0.001$ & \multirow{7}{*}{0.369} & \multirow{7}{*}{0.765} & \multirow{7}{*}{0.649} \\
\hline & $X_{9}$ & 0.810 & $<0.001$ & & & \\
\hline & $X_{10}$ & 0.222 & $<0.001$ & & & \\
\hline & $X_{11}$ & 0.798 & $<0.001$ & & & \\
\hline & $X_{12}$ & 0.714 & $<0.001$ & & & \\
\hline & $X_{13}$ & 0.598 & $<0.001$ & & & \\
\hline & $X_{14}$ & 0.035 & 0.236 & & & \\
\hline \multirow{5}{*}{ Travel experience $\eta_{1}$} & $Y_{1}$ & 0.682 & $<0.001$ & \multirow{5}{*}{0.588} & \multirow{5}{*}{0.829} & \multirow{5}{*}{0.705} \\
\hline & $Y_{2}$ & 0.919 & $<0.001$ & & & \\
\hline & $Y_{3}$ & 0.918 & $<0.001$ & & & \\
\hline & $Y_{4}$ & 0.859 & $<0.001$ & & & \\
\hline & $Y_{5}$ & 0.217 & $<0.001$ & & & \\
\hline \multirow{4}{*}{ Attitude $\eta_{2}$} & $Y_{6}$ & 0.714 & $<0.001$ & \multirow{4}{*}{0.619} & \multirow{4}{*}{0.866} & \multirow{4}{*}{0.794} \\
\hline & $Y_{7}$ & 0.824 & $<0.001$ & & & \\
\hline & $Y_{8}$ & 0.789 & $<0.001$ & & & \\
\hline & $Y_{9}$ & 0.816 & $<0.001$ & & & \\
\hline
\end{tabular}

indicates the values of AVE square root for latent variables, through the reflective and formative indicators. For the variables of transport infrastructure and services $\left(\xi_{1}\right)$, as well as travel experience $\left(\eta_{1}\right)$ and attitude $\left(\eta_{2}\right)$, the values of AVE square root were greater than other latent variables, as observed in both rows and columns within the table. The AVE square root value for transport infrastructure and services was 0.596 , which was found to be greater than other variables in the same column. Furthermore, the AVE root value of travel experience and attitude were similarly larger than other variables. The square root of AVEs were also applied to formative indicators [73], as Table 4 showed that the value for work characteristics $\left(\xi_{1}\right)$ was smaller than the one in the same column. All indicators that did not meet the discriminant validity requirements were considered for exclusion from the model.

The next stage was to test the reliability of the reflective indicators using composite reliability and Cronbach's alpha values, which should both be greater than 0.7 [68]. The results showed that both values were $>0.7$ for the reflective indicators except for the Cronbach alpha value for transport infrastructure and services (see Table 3). Therefore, the indicators that did not meet the loading value requirements were removed from the model, in order for the transport infrastructure and services to achieve the optimum standard.

The formative model was evaluated by testing the significance of indicator weights and multicollinearity, using the respective parameters of $p<0.05$ and VIF $<5$ [73]. Based on these conditions, $X_{20}$ and $X_{26}$ did not meet the criteria (see Table 5).

Overall, indicators $X_{10}, X_{14}, X_{20}, X_{26}$, and $Y_{5}$ did not meet the validity and reliability requirements. Also, the transport infrastructure and services and work characteristics variables did not achieve validity. All indicators that did not meet the requirements were excluded from the model. Based on the exclusion of these indicators, re-analysation was carried out, as the AVE and Cronbach's alpha values of the transport infrastructure and services variable were 0.511 $(>0.5)$ and $0.755(>0.7)$, which met the convergent validity and reliability requirements, respectively. Additionally, the square root of AVEs for the work characteristics changed to 0.564 , which was greater than that of other variables. This indicates that the work characteristics meet the FornellLarcker criteria to be able to be used in the model.

4.2. Structural Model. Generally, a model is considered to perform well if it has accurate predictive ability, based on the coefficients of $Q^{2}>0$ and $R^{2}>0.02$, while also being free of multicollinearity $[68,75]$. Table 6 shows that the $R^{2}$ and $Q^{2}$ values of all endogenous variables met these requirements. The $R^{2}$ value of 0.413 indicated that the effect of the exogenous variable (stimulus) on the travel experience $\left(\eta_{1}\right)$ was $41.3 \%$, with the remainder being influenced by other external factors. The $R^{2}$ value shows that the structural model explained $41.3 \%$ of the variance in the travel experience. Likewise, for attitude $\left(\eta_{2}\right)$, the structural model explained $66.2 \%$ of the variance, which indicates the influence of the stimulus and travel experience variables.

However, the influence of organism travel experience and attitude on the choice of transport mode was $9.4 \%$, $12.2 \%$, and $23.9 \%$ for public transport $\left(\eta_{3}\right)$, private transport $\left(\eta_{4}\right)$, and e-hailing usages $\left(\eta_{5}\right)$, respectively. The value of $R^{2}$ was lowest for public transport usage, revealing the small influence of travel experience and attitude on this mode choice, even though the minimum requirement $(>0.02)$ was met. Besides travel experience and attitude, the low $R^{2}$ value showed that variables outside the scope of this study influenced the choice of public transport, although each factor (travel experience and attitude) had a significant effect. Table 6 also indicates that the value of full collinearity (VIFs) for each variable was $<3.3$, following the conditions stated by Kock [73].

Finally, the evaluation of this structural model also included the value of goodness of fit $(\mathrm{GoF})$. The GoF refers to the value of "Tenenhaus GoF" in WarpPLS, which is used as a measure of the model's explanatory power where small$\geq 0.1$, medium $\geq 0.25$, and large $\geq 0.36$ [73]. The results 
TABle 4: Assessment of discriminant validity based on the Fornell-Larcker criteria.

\begin{tabular}{lcccccccc}
\hline Variable & $\xi_{1}$ & $\xi_{2}$ & $\xi_{3}$ & $\xi_{4}$ & $\eta_{1}$ & $\eta_{2}$ & $\eta_{3}$ & $\eta_{4}$ \\
\hline$\xi_{1}$ & $\mathbf{0 . 5 9 6}$ & & & & & & & \\
$\xi_{2}$ & -0.047 & $\mathbf{0 . 6 0 8}$ & & & & & \\
$\xi_{3}$ & 0.123 & 0.539 & $\mathbf{0 . 6 6 4}$ & & & & \\
$\xi_{4}$ & 0.006 & 0.358 & 0.466 & $\mathbf{0 . 4 9}$ & & & \\
$\eta_{1}$ & -0.025 & 0.307 & 0.523 & 0.533 & $\mathbf{0 . 7 6 7}$ & & & \\
$\eta_{2}$ & 0.113 & 0.618 & 0.571 & 0.566 & 0.575 & $\mathbf{0 . 7 8 7}$ & \\
$\eta_{3}$ & -0.16 & 0.321 & -0.045 & -0.15 & -0.126 & 0.018 & $\mathbf{0 . 6 9 2}$ & \\
$\eta_{4}$ & 0.366 & 0.029 & 0.329 & 0.359 & 0.326 & 0.232 & -0.526 & $\mathbf{0 . 5 9}$ \\
$\eta_{5}$ & -0.204 & 0.406 & 0.335 & 0.33 & 0.32 & 0.437 & 0.058 & -0.005 \\
\hline
\end{tabular}

TABLE 5: Indicator weights for formative variables.

\begin{tabular}{|c|c|c|c|}
\hline \multirow{2}{*}{ Variable } & \multirow{2}{*}{ Indicator } & \multicolumn{2}{|c|}{ Indicator weights } \\
\hline & & $p$ value & VIF \\
\hline \multirow{7}{*}{ Trip characteristics $\xi_{1}$} & $X_{1}$ & $<0.001$ & 1.262 \\
\hline & $X_{2}$ & $<0.001$ & 1.644 \\
\hline & $X_{3}$ & $<0.001$ & 1.771 \\
\hline & $X_{4}$ & 0.046 & 1.295 \\
\hline & $X_{5}$ & 0.005 & 1.311 \\
\hline & $X_{6}$ & $<0.001$ & 2.02 \\
\hline & $X_{7}$ & $<0.001$ & 2.118 \\
\hline \multirow{5}{*}{ Environment $\xi_{3}$} & $X_{15}$ & $<0.001$ & 1.177 \\
\hline & $X_{16}$ & $<0.001$ & 1.532 \\
\hline & $X_{17}$ & $<0.001$ & 1.418 \\
\hline & $X_{18}$ & $<0.001$ & 1.136 \\
\hline & $X_{19}$ & $<0.001$ & 1.253 \\
\hline \multirow{8}{*}{ Work characteristics $\xi_{4}$} & $X_{20}$ & 0.249 & 1.068 \\
\hline & $X_{21}$ & $<0.001$ & 1.271 \\
\hline & $X_{22}$ & $<0.001$ & 1.308 \\
\hline & $X_{23}$ & $<0.001$ & 1.274 \\
\hline & $X_{24}$ & $<0.001$ & 1.164 \\
\hline & $X_{25}$ & $<0.001$ & 1.178 \\
\hline & $X_{26}$ & 0.089 & 1.134 \\
\hline & $X_{27}$ & $<0.001$ & 1.15 \\
\hline \multirow{2}{*}{ Public transport usage $\eta_{3}$} & $Y_{10}$ & $<0.001$ & 1.002 \\
\hline & $Y_{11}$ & $<0.001$ & 1.002 \\
\hline \multirow{2}{*}{ Private transport usage $\eta_{4}$} & $Y_{12}$ & $<0.001$ & 1.101 \\
\hline & $Y_{13}$ & $<0.001$ & 1.101 \\
\hline \multirow{2}{*}{ e-hailing usage $\eta_{5}$} & $Y_{14}$ & $<0.001$ & 1.351 \\
\hline & $Y_{15}$ & $<0.001$ & 1.351 \\
\hline
\end{tabular}

TABLE 6: The assessment of the predictive validity and multicollinearity for latent variables.

\begin{tabular}{lccccccccc}
\hline Latent variable coefficients & \multicolumn{3}{c}{ Variable } & \multicolumn{3}{c}{$\eta_{3}$} & $\eta_{4}$ \\
& $\xi_{1}$ & $\xi_{2}$ & $\xi_{3}$ & $\xi_{4}$ & $\eta_{1}$ & $\eta_{2}$ & 0.122 & 0.239 \\
$R^{2}$ & & & & & 0.413 & 0.662 & 0.094 & 0.13 \\
$Q^{2}$ & & & & & 0.416 & 0.662 & 0.088 & 0.124 & 0.243 \\
VIFs & 1.332 & 2.277 & 1.963 & 1.755 & 1.942 & 2.644 & 1.696 & 1.939 & 1.416 \\
\hline
\end{tabular}

indicate that the GoF value of the structural model was 0.394 , illustrating that the explanatory power of the model was large.

Path coefficient analysis was conducted to test the relationships between the stimulus, organism, and response variables. Figure 3 shows the results, including $p$ values and path coefficients. First, the relationships between the stimulus and organism variables were analysed. The results revealed that both the environmental variable and work characteristics were significantly related to travel experience with path coefficients $(\gamma)$ of 0.358 and 0.377 , respectively. Similarly, trip characteristics, work characteristics, and 


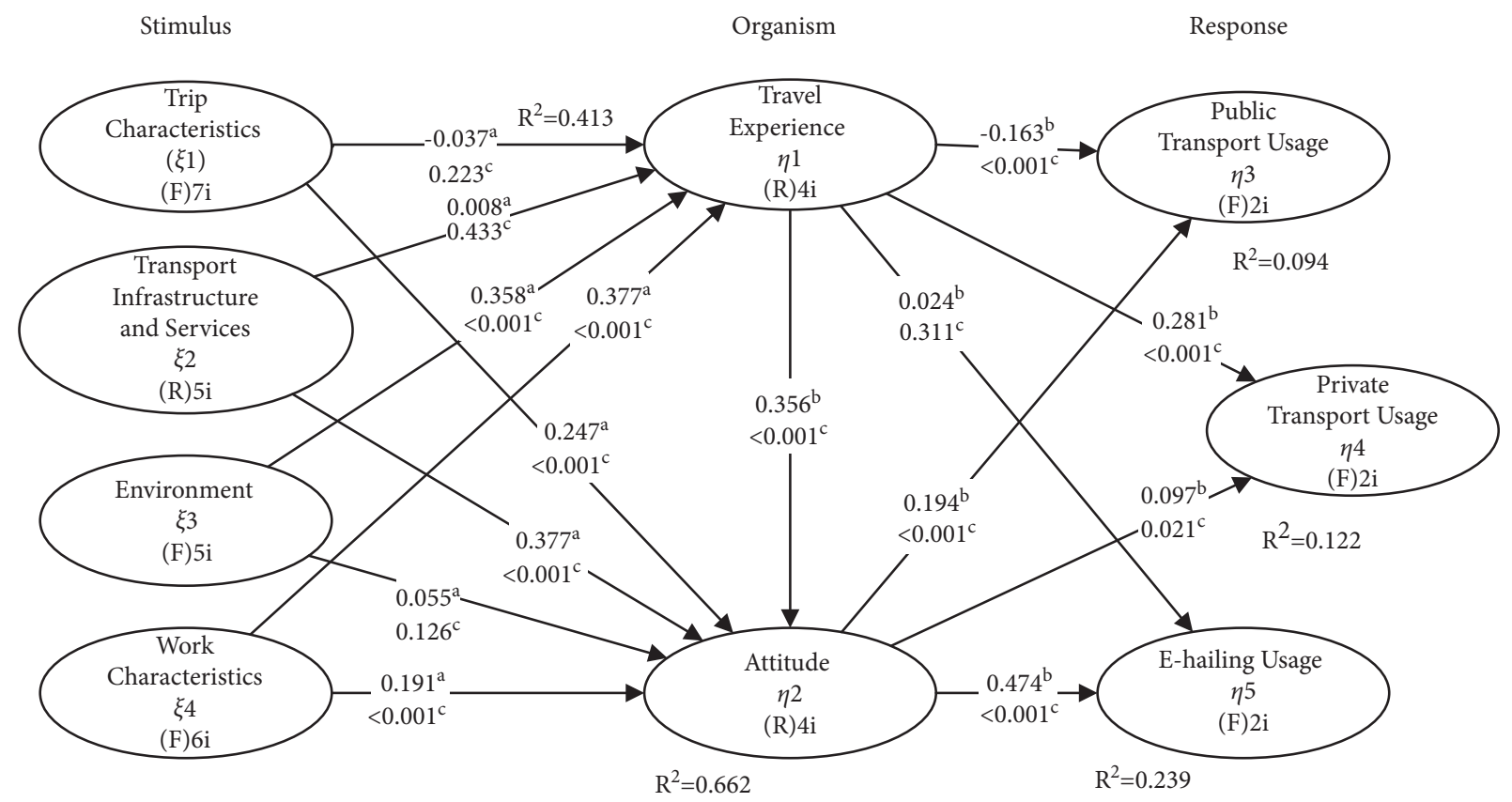

Figure 3: The structural model. Note: ${ }^{a}$ path coefficients $(\gamma)$; ${ }^{b}$ path coefficients $(\beta) ;{ }^{c} p$ value; and GoF index $=0.394$.

transport infrastructure and services were each significantly related to attitude with path coefficients of $0.247,0.191$, and 0.377 , respectively. Secondly, the relationship between the organism and response variables were analysed, as the results showed that travel experience was significantly $(p<0.001)$ related to the choice of public transport, with a negative $(-0.163)$ and positive $(0.281)$ path coefficients $(\beta)$ on private transport usage. However, it was not significant to the choice of e-hailing. In contrast to travel experience, the attitude variable was significantly related to all three transport mode choices. The path coefficient of the influence of attitude on public transport usage was $\beta=0.194$ and significant at $p<0.001$, private transport usage $\beta=0.097$ and $p<0.021$, and e-hailing usage $\beta=0.474$ and $p<0.001$.

This structural analysis tested the indirect effects between variables in the model consistent with the hypothesis in Figure 2. The indirect effects and their levels of significance were analysed. Table 7 reports the results. The results show that there were significant indirect effects found for 6 of the hypotheses on indirect effects between stimulus variables and the choice of transport mode. The indirect effect of the trip characteristics variable was positive with a total effect of 0.11 and $p$ value $<0.05$ on the use of e-hailing, following hypothesis 3 (H3). Furthermore, a significant indirect effect on e-hailing usage was also obtained from transport infrastructure and services (H6) of 0.18 with $p$ value $<0.001$, environment (H9) of 0.094 with $p$ value $<0.05$, and the effect of work characteristics (H12) of 0.162 with $p$ value $<0.001$. These findings show that transport infrastructure and services had a greater influence than other variables. Meanwhile, the environment variable also had a significant effect on private transport choice according to hypothesis 8 (H8) of 0.118 with a $p$ value $<0.05$. The effect of environment was slightly lower than that of work characteristics (H11) at 0.137 and $p$ value $<0.05$.
Finally, the indirect correlation between travel experience and mode of transport through attitude shows that there was a significant relationship with the choice of public transport according to hypothesis 13 (H13) with a total effect of 0.069 and $p$ value $<0.05$. However, travel experience also had a significant direct effect on public transport choice by negative 0.613 , indicating that the total effect of the travel experience was negative 0.094. Travel experience also had a significant indirect effect on the selection of e-hailing of 0.169 with $p$ value $<0.05$, consistent with hypothesis 15 (H15) and also had a direct effect of 0.024, indicating that the total effect on e-hailing usage was 0.192 .

4.3. Discussion. This study applies the SOR model to understand mode choice behaviour on commuting to work. The results of the hypothesis test show that the indirect effects of the stimulus variables are not significant in the selection of public transport, but are significant for the selection of e-hailing and private transport. Meanwhile, the indirect relationship between travel experience and transport mode through attitude indicates a significant effect on the choice of public transport and e-hailing. From the total effect of each significant relationship (Table 7), it can be seen that in general the total effects were positive, except that the relationship between travel experience and public transport usage was negative. This indicates that the SOR model developed in this study found more of an effect on increasing the use of e-hailing and private transport.

The positive influence of stimulus variables through organism variables on e-hailing usage is understood in the context of Jakarta. This is because access to using e-hailing is very easy with tariffs determined based on distance and traffic conditions [76]. The ease of using e-hailing services is supported by the provision of transport infrastructure in 
TABLE 7: The validation of direct, indirect, and total effect.

\begin{tabular}{|c|c|c|c|c|c|}
\hline Indirect relations & $\begin{array}{c}\text { Direct } \\
\text { effect }\end{array}$ & $\begin{array}{l}\text { Indirect effects 2- } \\
\text { segment }\end{array}$ & $\begin{array}{c}\text { Indirect effects 3- } \\
\text { segment }\end{array}$ & $\begin{array}{l}\text { Total } \\
\text { effect }\end{array}$ & $\begin{array}{c}p \\
\text { values }\end{array}$ \\
\hline Trip characteristics-public transport usage & - & 0.054 & -0.003 & 0.051 & 0.141 \\
\hline Trip characteristics-private transport usage & - & 0.014 & -0.001 & 0.013 & 0.398 \\
\hline Trip characteristics-e-hailing usage & - & 0.116 & -0.006 & 0.11 & 0.011 \\
\hline $\begin{array}{l}\text { Transport infrastructure and services-public } \\
\text { transport usage }\end{array}$ & - & 0.072 & 0.001 & 0.073 & 0.065 \\
\hline $\begin{array}{l}\text { Transport infrastructure and services-private } \\
\text { transport usage }\end{array}$ & - & 0.039 & 0 & 0.04 & 0.207 \\
\hline Transport infrastructure and services-e-hailing usage & - & 0.179 & 0.001 & 0.18 & $<0.001$ \\
\hline Environment-public transport usage & - & -0.048 & 0.025 & -0.023 & 0.316 \\
\hline Environment-private transport usage & - & 0.106 & 0.012 & 0.118 & 0.007 \\
\hline Environment-e-hailing usage & - & 0.034 & 0.06 & 0.094 & 0.024 \\
\hline Work characteristics-public transport usage & - & -0.024 & 0.026 & 0.002 & 0.487 \\
\hline Work characteristics-private transport usage & - & 0.124 & 0.013 & 0.137 & 0.002 \\
\hline Work characteristics-e-hailing usage & - & 0.099 & 0.063 & 0.162 & $<0.001$ \\
\hline Travel experience-public transport usage & -0.163 & 0.069 & - & -0.094 & 0.021 \\
\hline Travel experience-private transport usage & 0.281 & 0.035 & - & 0.316 & 0.154 \\
\hline Travel experience-e-hailing usage & 0.024 & 0.169 & - & 0.192 & $<0.001$ \\
\hline Attitude-public transport usage & 0.194 & - & - & 0.194 & $<0.001$ \\
\hline Attitude-private transport usage & 0.094 & - & - & 0.094 & 0.021 \\
\hline Attitude-e-hailing usage & 0.474 & - & - & 0.474 & $<0.001$ \\
\hline
\end{tabular}

Jakarta, which currently leads to sustainable transport [48]. Furthermore, accessibility and connectivity between modes and the development of information technology that supports travel have allowed the use of e-hailing to become an alternative capable of competing with other modes of commuting. In fact, in Indonesia, users of e-hailing services generally feel safe and comfortable, with various innovations that make the services reliable $[4,5]$. Munandar and Munthe [45] stated that in Thailand perceptions of comfort and security are also factors that influence the use of e-hailing. Salim et al. [46] reported that these factors also influence the adoption of e-hailing services in Kuala Lumpur, Malaysia. However, a study conducted by Zhong et al. [47] stated that people working in public management in Shanghai, China, have a low interest in e-hailing services.

Moreover, a total positive effect also occurred in the relationship between the environment and the choice of private transport, as well as between job characteristics and the choice of private transport. This positive effect is understandable because Jakarta is a dense urban environment comprising of residents and buildings. Therefore, adequate accessibility tends to promote the use of private transport due to the poor perception of the public counterpart. This is in line with the research carried out in Melbourne, Australia, which found that a congested environment negatively affects the use of buses and trains within the city [59]. However, this finding was in contrast with the opinion expressed by Vos and Ettema [58], which stated that in dense and diverse environmental areas, people prefer to use public transport rather than cars. Ding et al. [36] found that in Baltimore metropolitan area, United States, that environmental diversity increased the use of public transport. In the case of this study, the mediating effect of organismal variables may be the cause of this finding, which is in contrast to some of the previous studies described above.
Next, the significant influence of work characteristics on the choice of private transport strengthens understanding of the role played by office management in controlling the use of cars and motorcycles. Ermans et al. [40] reported from a study in Belgium that employers could exercise control over private car use through office policies providing incentives for employees that make use of public transport to get to work or allowing flexible job schedules. Ton et al. [38] also revealed that work duration had a significant effect on mode choice for commuting: specifically, the longer the working week, the greater the likelihood of choosing car and train. Furthermore, a study by Chu et al. [55] in Ho Chi Minh city, Vietnam, found that a decrease in working hours per week caused a reduction in the number of motorbike trips to work.

Finally, consistent with hypotheses H13, H14, and H15, travel experience can be assumed to act as a stimulus while attitude is an organism. Therefore, there is a relationship between travel experience-attitude-transport modes in the model. The results of the analysis show that the indirect effect was positive and significant on the use of public transport and e-hailing. However, the total effect on public transport usage was negative because there was a direct negative effect of travel experience on the use of public transport which was greater than the positive indirect effect (see Table 7). These results indicate that the mediating effect of attitude can reduce the negative effect of travel experience on public transport choice. This finding differs from the study conducted by $\mathrm{He}$ and Thøgersen [65] in Guangzhou, China, which found that positive attitudes towards sustainable transport did not affect the choice of public transport for commuting. However, on e-hailing choice, the total effect is greater than that of public transport usage, indicating that a pleasant travel experience can be obtained by using e-hailing if there is a positive attitude towards the environment, lifestyle, and job satisfaction. 
In short, the analysis of the SOR model using PLS-SEM shows that the organism travel experience and attitude variables can have a mediating effect on the stimulus that produces a particular mode choice response. This supports the main concept of the SOR model, namely, that response to a choice is a process of managing a stimulus through an emotional approach (organism) such as pleasure, passion, or experience [27]. In other words, the commuters in this study consider it important to have a travel experience that meets the criteria of being reliable, comfortable, safe, and secure during commuting.

4.4. Implications. The discussion above shows that the application of the SOR model did not have a significant effect on the likelihood of selecting public transport. This was due to the mediation effect of the organism variables of travel experience and attitude. This study showed the need to improve the reliability, security, comfort, and safety of public transport for commuters working within the city. Therefore, continuing improvement of public transport services is necessary to increase workers' inclination to use public transport for commuting. Service has been identified as a significant public transport problem that often leads people to preferring to use private transport, especially in developing countries [1]. Service involved timeliness (departure and arrival periods), availability, and affordability. Therefore, control systems and mechanisms for services application should be adequately regulated. At the same time, a wider campaign is needed on the importance of urban sustainable transport for sustainable development. The provision of transport services with network-based and modern technology standards can change travel behaviour to be more sustainable and make it a lifestyle.

The environment should also be designed by considering density (e.g., residential, employment, and route) and maintaining diversity. Furthermore, land use in new urban areas should be highly mixed. Housing and workplaces should also be proximally located, in order to decrease travel time and distance, as well as have a positive impact on trip requirements reduction. Within existing urban areas, there is a need for revitalisation by increasing access to public transport and facilitating nonmotorised mobility. This study's results further showed the significant influence of work characteristics on commuters' preference for using private transport. Employers can play a key role through introducing flexible working hours, incentivising the use of public transport [40], and limitations of parking policies at work [41].

The improvement of public transport services, constructed environment, flexibility of working hours, and incentives can be integrated into the avoid-shift-improve (ASI) strategy. This strategy is used in order to achieve a sustainable transport process, through reducing the need for travel (avoid), promoting the use of public transport (shift), and improving the energy efficiency of commute modes (improve) [49]. Revitalisation of the environment, building new mixed areas, and flexibility of working hours all represent avoidance efforts; the continuous improvement of public transport services and incentivising their use represent shifts, while the use of electric buses and e-hailing represent efforts to improve. The proposals of job hour flexibility and public transport incentives were also policies outside the transport system. Therefore, the integration of job hours flexibility and incentives into the ASI concept is expected to increase the preference for using public transport.

4.5. Limitations. The main limitation was the use of the original SOR model, which assumed that the organism variable was a complete mediation, in order for the path diagram to achieve one-dimensional form. This form in the PLS-SEM indicated that changes in endogenous variables were influenced by alterations in the mediating indicators, due to differences in the exogenous factors. This result seemed to be biased: a comprehensive interpretation requires two-dimensional analysis, namely, of direct and indirect pathways [77]. However, several studies that previously applied the SOR model also used SEM with onedimensional path diagrams and effectively explained the indirect relationships [21, 70]. Nitzl et al. [78] also suggested that a direct-effect analysis should be carried out before conducting the mediation test, as there is no definite guide for mediation analysis using PLS-SEM.

\section{Conclusions}

The study aims to apply the SOR model to understand commuters' transport mode choice behaviour. The SOR model showed that the stimulus variables significantly influence the choice of transport mode responses via the organism variables. The trend of this effect showed that there were more stimulus variables that had a significant influence on e-hailing usage than on private transport via the organism factors. However, these variables did not have a significant effect on public transport usage via the organism factors. When travel experience and attitude were considered as the respective stimulus and organism variables, there was a significantly positive indirect effect on choice of public transport. Meanwhile, environment and work characteristics contributed to increasing commuters' preference for using private transport. This mode of choice behaviour also depended on the provided stimulus and organism. Based on the same organism and different stimuli variables, SOR analysis produced identical and distinguished responses.

In addition to strengthening transport services by increasing reliability, security, comfort, and safety, environmental arrangements should be considered to improve accessibility to public transport and nonmotorised mobility for both residential and office areas. Furthermore, building new and more diverse environments, as well as revitalising existing environments, is among the key steps needed to support the development of sustainable transport. Employers can also play an important role in providing a stimulus for sustainable transport adoption. Given the notable increase in the use of e-hailing offering several conveniences at affordable prices, use of electric vehicles in these services should be mandated. 
This case study which was carried out in Jakarta using the SOR model has strengthened the global evidence base for realising sustainable urban transport in an integrated manner. Furthermore, the SOR model contributed to explaining travel behaviour as a basis for formulating appropriate policies. Further studies need to be conducted, by integrating several external policies, such as the integration of public transport incentives and job hour's flexibility into the avoid-shift-improve strategy. Additionally, further study on the application and development of the SOR model in mode choice behaviour based on consumer behaviour theory is also recommended.

\section{Data Availability}

The datasets analysed during this study are not available for publication, but reasonable requests for access can be made through the corresponding author, with disclosure subject to approval by the Ministry of Education, Culture, Research and Technology of the Republic of Indonesia, as well as the Directorate General of Higher Education.

\section{Conflicts of Interest}

The authors declare that there are no conflicts of interest regarding the publication of this study.

\section{Acknowledgments}

This study was supported by the Ministry of Research and Technology, National Research and Innovation Agency of the Republic of Indonesia in 2020, and the Ministry of Education, Culture, Research and Technology in 2021, through the doctoral dissertation research scheme.

\section{References}

[1] Z. Adam, L. Walasek, and C. Meyer, "Workforce commuting and subjective well-being," Travel Behaviour and Society, vol. 13, pp. 183-196, 2018.

[2] J. Yang, H. Kato, R. Ando, and Y. Nishihori, "Analyzing household vehicle ownership in the Japanese local city: case study in toyota city," Journal of Advanced Transportation, vol. 2020, Article ID 7264860, 7 pages, 2020.

[3] M. L. Delgado Jalón, A. Gómez Ortega, and J. De Esteban Curiel, "The social perception of urban transport in the city of Madrid: the application of the servicescape model to the bus and underground services," European Transport Research Review, vol. 11, no. 37, pp. 1-11, 2019.

[4] S. L. B. Silalahi, P. W. Handayani, and Q. Munajat, "Service quality analysis for online transportation services: case study of GO-JEK," Procedia Computer Science, vol. 124, pp. 487495, 2017.

[5] R. Septiani, P. W. Handayani, and F. Azzahro, "Factors that affecting behavioral intention in online transportation service: case study of GO-JEK," Procedia Computer Science, vol. 124, pp. 504-512, 2017.

[6] F. Ahmed, J. Catchpole, and T. Edirisinghe, "Understanding young commuters' mode choice decision to use private car or public transport from an extended theory of planned behavior," Transportation Research Record: Journal of the
Transportation Research Board, vol. 2675, no. 3, pp. 200-211, 2020.

[7] I. Ajzen, "The theory of planned behavior," Organizational Behavior and Human Decision Processes, vol. 50, no. 2, pp. 179-211, 1991.

[8] J. Lee, F. Baig, and A. Pervez, "Impacts of COVID-19 on individuals' mobility behavior in Pakistan based on self-reported responses," Journal of Transport \& Health, vol. 22, no. 2021, pp. 1-17, 2021.

[9] M. I. Ajzen and A. Fishbein, Understanding Attitudes and Predicting Social Behaviour, Prentice-Hall, Englewood Cliffs, NJ, USA, 1980.

[10] M. E. Ben-Akiva and S. R. Lerman, Discrete Choice Analysis: Theory and Application to Travel Demand, MIT Press, Cambridge, MA, USA, 1985.

[11] K. Shaaban and A. Maher, "Using the theory of planned behavior to predict the use of an upcoming public transportation service in Qatar," Case Studies on Transport Policy, vol. 8, no. 2, pp. 484-491, 2020.

[12] O. A. Bjørkelund, H. Degerud, and E. Bere, "Socio-demographic, personal, environmental and behavioral correlates of different modes of transportation to work among Norwegian parents," Archives of Public Health, vol. 74, no. 43, pp. 43-49, 2016.

[13] F. L. Mayo and E. B. Taboada, "Ranking factors affecting public transport mode choice of commuters in an urban city of a developing country using analytic hierarchy process: the case of Metro Cebu, Philippines," Transportation Research Interdisciplinary Perspectives, vol. 4, pp. 1-12, 2020.

[14] I. C. Athira, C. P. Muneera, K. Krishnamurthy, and M. V. L. R. Anjaneyulu, "Estimation of value of travel time for work trips," Transportation Research Procedia, vol. 17, no. 2016, pp. 116-123, 2016.

[15] M. Gaudry, “The utility of journeys, from Dupuit's constanttime bridge crossing hops to commutes of chosen duration and reliability in the Paris region," Transport Policy, vol. 70, pp. 53-68, 2018.

[16] H. Asgari and X. Jin, "An evaluation of part-day telecommute impacts on work trip departure times," Travel Behaviour and Society, vol. 12, pp. 84-92, 2018.

[17] R. Huang, "Simulating individual work trips for transit-facilitated accessibility study," Environment and Planning B: Urban Analytics and City Science, pp. 1-19, 2017.

[18] L. Cheng, X. Chen, S. Yang, J. Wu, and M. Yang, "Structural equation models to analyze activity participation, trip generation, and mode choice of low-income commuters," Transportation Letters, vol. 11, no. 6, pp. 341-349, 2017.

[19] A. Plavara Alex, M. Vasudevan Saraswathy, and K. Palampoikayil Isaac, "Latent variable enriched mode choice model for work activity in multi modal condition prevalent in India," International Journal of Traffic and Transportation Engineering, vol. 6, no. 4, pp. 378-389, 2016.

[20] A. Mehrabian and J. A. Russel, An Approach to Environmental Psychology, MIT Press, Cambridge, MA, USA, 1974.

[21] M.-H. Li, "Exploring short video application users' visit intention: applying the stimulus-organism-response model," Asian Social Science, vol. 15, no. 12, pp. 8-19, 2019.

[22] M. T. Goi, V. Kalidas, and M. Zeeshan, "Comparison of stimulus-organism-response framework between international and local retailer," Procedia-Social and Behavioral Sciences, vol. 130, pp. 461-468, 2014.

[23] A. H. Ngah, H. D. Kim, R. M. Hanafiah, N. H. M. Salleh, J. Jeevan, and N. M. Asri, "Willingness to pay for Halal transportation cost: the Stimulus-organism-response model," 
International Journal of e-Navigation and Maritime Economy, vol. 12, pp. 11-21, 2019.

[24] R. Othman, R. Musa, M. Muda, and R. N. Mohamed, "Conceptualization of immersive brand experience (IBX) measurement scale of emotion," Procedia Economics and Finance, vol. 37, pp. 208-213, 2016.

[25] M. Dzandu, B. Pathak, and S. Gulliver, "Stimulus-OrganismResponse model for understanding autonomous vehicle adoption in the UK," in Proceedings of the BAM2020 Conference in the Cloud, Manchester, UK, September 2020.

[26] A. Mehrabian and J. A. Russell, "The basic emotional impact of environments," Perceptual \& Motor Skills, vol. 38, no. 1, pp. 283-301, 1974.

[27] J. Jacoby, "Stimulus-organism-response reconsidered: an evolutionary step in modeling (consumer) behavior," Journal of Consumer Psychology, vol. 12, no. 1, pp. 51-57, 2002.

[28] S. Chakrabarti, "How can public transit get people out of their cars? An analysis of transit mode choice for commute trips in Los Angeles," Transport Policy, vol. 54, pp. 80-89, 2017.

[29] D. Papaioannou and L. M. Martinez, "The role of accessibility and connectivity in mode choice. A structural equation modeling approach," Transportation Research Procedia, vol. 10, pp. 831-839, 2015.

[30] J. Gutiérrez and P. Urbano, "Accessibility in the European Union: the impact of the trans-European road network," Journal of Transport Geography, vol. 4, no. 1, pp. 15-25, 1996.

[31] P. Parthasarathi and D. Levinson, "Network structure and the journey to work: an intra-metropolitan analysis," Transportation Research Part A: Policy and Practice, vol. 118, pp. 292-304, 2018.

[32] W. Li, W. Feng, and H. Z. Yuan, "Multimode traffic travel behavior characteristics analysis and congestion governance research," Journal of Advanced Transportation, vol. 2020, Article ID 6678158, 8 pages, 2020.

[33] R. Arroyo, T. Ruiz, D. Casquero, and L. Mars, "Trip characteristics analysis of the effects of a travel behavior change program," Transportation Research Record: Journal of the Transportation Research Board, vol. 2672, no. 47, pp. 146-158, 2018.

[34] A. Ilahi, P. F. Belgiawan, and K. W. Axhausen, "Influence of pricing on mode choice decision integrated with latent variable," in Mapping the Travel Behavior Genome, K. G. Goulias and A. W. Davis, Eds., pp. 125-143, Elsevier, Amsterdam, Netherlands, 2020.

[35] M. T. Tran, J. Zhang, M. Chikaraishi, and A. Fujiwara, "A joint analysis of residential location, work location and commuting mode choices in Hanoi, Vietnam," Journal of Transport Geography, vol. 54, pp. 181-193, 2016.

[36] C. Ding, D. Wang, C. Liu, Y. Zhang, and J. Yang, "Exploring the influence of built environment on travel mode choice considering the mediating effects of car ownership and travel distance," Transportation Research Part A: Policy and Practice, vol. 100, pp. 65-80, 2017.

[37] S. Ramezani, B. Pizzo, and E. Deakin, "An integrated assessment of factors affecting modal choice: towards a better understanding of the causal effects of built environment," Transportation, vol. 45, no. 5, pp. 1351-1387, 2018.

[38] D. Ton, S. Bekhor, O. Cats, D. C. Duives, S. HoogendoornLanser, and S. P. Hoogendoorn, "The experienced mode choice set and its determinants: commuting trips in The Netherlands," Transportation Research Part A: Policy and Practice, vol. 132, pp. 744-758, 2020.

[39] K. M. Nurul Habib, "Modeling commuting mode choice jointly with work start time and work duration,"
Transportation Research Part A: Policy and Practice, vol. 46, no. 1, pp. 33-47, 2012.

[40] T. Ermans, C. Brandeleer, M. Hubert, K. Lebrun, and F. Sieux, "Travel between home and work: current situation and perspectives for action for companies BSI synopsis," Brussels Studies, vol. 125, pp. 1-32, 2018.

[41] H. Batista Ferrer, A. Cooper, and S. Audrey, "Associations of mode of travel to work with physical activity, and individual, interpersonal, organisational, and environmental characteristics," Journal of Transport \& Health, vol. 9, pp. 45-55, 2018.

[42] E. Heinen and W. Bohte, "Multimodal commuting to work by public transport and bicycle," Transportation Research Record: Journal of the Transportation Research Board, vol. 2468, no. 1, pp. 111-122, 2014.

[43] K. Chatterjee, S. Chng, B. Clark et al., "Commuting and wellbeing: a critical overview of the literature with implications for policy and future research," Transport Reviews, vol. 40, no. 1, pp. 5-34, 2020.

[44] J. Chen and S. Li, "Mode choice model for public transport with categorized latent variables," Mathematical Problems in Engineering, vol. 2017, Article ID 7861945, 11 pages, 2017.

[45] J. Munandar and R. Munthe, "How technology affects behavioral intention (case study of online transportation in Indonesia and Thailand)," South East Asian Journal of Management, vol. 13, no. 2, pp. 222-236, 2019.

[46] S. Salim, M. Azim, M. Azmi, M. E. Sanik, and A. H. Mat, "Factors influencing passengers' use of E-hailing services in Malaysia," International Journal of Engineering and Advanced Technology, vol. 9, no. 3, pp. 2711-2714, 2020.

[47] J. Zhong, X. Ye, K. Wang, and D. Li, "A modeling analysis of impact from E-hailing service on non-work travel mode in Shanghai, China," Transportation Research Record, vol. 2672, no. 47, pp. 125-134, 2018.

[48] P. A. Nadi and A. K. Murad, "Modelling sustainable urban transport performance in the Jakarta city Region: a GIS approach," Sustainable Times, vol. 11, no. 7, 2019.

[49] S. Bakker, M. Zuidgeest, H. de Coninck, and C. Huizenga, "Transport, development and climate change mitigation: towards an integrated approach," Transport Reviews, vol. 34, no. 3, pp. 335-355, 2014.

[50] Y. Liu, Y. Ji, Z. Shi, B. He, and Q. Liu, "Investigating the effect of the spatial relationship between home, workplace and school on parental chauffeurs' daily travel mode choice," Transport Policy, vol. 69, pp. 78-87, 2018.

[51] D. Deka, "An explanation of the relationship between adults' work trip mode and children's school trip mode through the Heckman approach," Journal of Transport Geography, vol. 31, pp. 54-63, 2013.

[52] M. K. A. Anderson, "Characteristics of trips and travellers in private and public transportation in the Danish travel survey data," Proceedings from the Annual Transport Conference at Aalborg University, vol. 28, pp. 1-16, 2010.

[53] M. G. McNally, "The four step model permalink," in Handbook of Transport Modell, pp. 35-41, Emerald, Bingley, UK, 2000.

[54] O. Skorobogatova and I. Kuzmina-Merlino, "Transport infrastructure development performance," Procedia Engineering, vol. 178, pp. 319-329, 2017.

[55] M. C. Chu, L. X. Nguyen, T. T. Ton, and N. Huynh, “Assessment of motorcycle ownership, use, and potential changes due to transportation policies in Ho Chi Minh city, Vietnam," Journal of Transportation Engineering Part A System, vol. 145, no. 12, pp. 1-11, 2019. 
[56] M. Irfan, A. N. Khurshid, M. B. Khurshid, Y. Ali, and A. Khattak, "Policy implications of work-trip mode choice using econometric modeling," Journal of Transportation Engineering Part A System, vol. 144, no. 8, pp. 1-10, 2018.

[57] H. Su, J. H. Wu, Y. Tan, Y. Bao, B. Song, and X. He, “A land use and transportation integration method for land use allocation and transportation strategies in China," Transportation Research Part A: Policy and Practice, vol. 69, pp. 329-353, 2014.

[58] J. De Vos and D. Ettema, "Travel and residential change: an introduction," Travel Behaviour and Society, vol. 19, pp. 3335, 2020.

[59] C. De Gruyter, L. Ma, T. Saghapour, and J. Dodson, "How does the built environment affect transit use by train, tram and bus?" Journal of Transport and Land Use, vol. 13, no. 1, pp. 625-650, 2020.

[60] E. Guerra, C. Caudillo, P. Monkkonen, and J. Montejano, "Urban form, transit supply, and travel behavior in Latin America: evidence from Mexico's 100 largest urban areas," Transport Policy, vol. 69, pp. 98-105, 2018.

[61] L. Böcker, M. Dijst, and J. Faber, "Weather, transport mode choices and emotional travel experiences," Transportation Research Part A: Policy and Practice, vol. 94, pp. 360-373, 2016.

[62] C. M. Alcover and G. Topa, "Work characteristics, motivational orientations, psychological work ability and job mobility intentions of older workers," PLoS One, vol. 13, no. 4, pp. 1-24, 2018.

[63] A. Ababio-Donkor, W. Saleh, and A. Fonzone, "Understanding transport mode choice for commuting: the role of affect," Transportation Planning and Technology, vol. 43, no. 4, pp. 385-403, 2020.

[64] Y. Han, W. Li, S. Wei, and T. Zhang, "Research on Passenger's travel mode choice behavior waiting at bus station based on SEM-logit integration Model," Sustainable Times, vol. 10, no. 6, pp. 1-23, 2018.

[65] S. Y. He and J. Thøgersen, "The impact of attitudes and perceptions on travel mode choice and car ownership in a Chinese megacity: the case of Guangzhou," Research in Transportation Economics, vol. 62, pp. 57-67, 2017.

[66] S. P. Washington, M. G. Karlaftis, and F. L. Mannering, Statistical and Econometric Methods for Transportation Data Analysis, CRC Press Taylor \& Francis Group, Boca Raton, Florida, Second edition, 2011.

[67] N. Kock, "Factor-based structural equation modeling with WarpPLS," Australasian Marketing Journal, vol. 27, 2018.

[68] J. F. Hair, J. J. Risher, M. Sarstedt, and C. M. Ringle, "When to use and how to report the results of PLS-SEM Abstract," European Business Review, vol. 31, no. 1, pp. 2-24, 2018.

[69] J. J. Hew, L. Y. Leong, G. W. H. Tan, V. H. Lee, and K. B. Ooi, "Mobile social tourism shopping: a dual-stage analysis of a multi-mediation model," Tourism Management, vol. 66, pp. 121-139, 2018.

[70] M. J. Kim, C. K. Lee, and T. Jung, "Exploring consumer behavior in virtual reality tourism using an extended stimulus-organism-response model," Journal of Travel Research, vol. 59 , no. 1 , pp. $69-89,2020$.

[71] Y. Huang and P. M. Bentler, "Behavior of asymptotically distribution free test statistics in covariance versus correlation structure analysis," Structural Equation Modeling, vol. 22, no. 4, pp. 489-503, 2015.

[72] T. Kim, S. Choo, Y. Shin, M. Park, and S. Iris You, "Identifying differences of travel time budgets between the elderly and the nonelderly groups using PSL structural equation models: a case study for Seoul metropolitan area," International Journal of Sustainable Transportation, vol. 10, no. 5, pp. 455-465, 2016.

[73] N. Kock, WarpPLS User Manual 6.0, ScriptWarp System, Laredo, TX, USA, 2019.

[74] WarpPLSTM, Nonlinear structural equation modeling made easy, https://www.warppls.com/.

[75] C. Fornell and D. F. Larcker, "Evaluating structural equation models with unobservable variables and measurement error," Journal of Marine Research, vol. 18, no. 1, pp. 39-50, 1981.

[76] S. Y. Wahyuningtyas, "The online transportation network in Indonesia: a pendulum between the sharing economy and ex ante regulation," Competition and Regulation in Network Industries, vol. 17, no. 3-4, pp. 260-280, 2016.

[77] X. Zhao, J. G. Lynch, and Q. Chen, "Reconsidering baron and kenny: myths and truths about mediation analysis," Journal of Consumer Research, vol. 37, no. 2, pp. 197-206, 2010.

[78] C. Nitzl, J. L. Roldan, and G. Cepeda, "Mediation analysis in partial least squares path modelling, Helping researchers discuss more sophisticated models," Industrial Management \& Data Systems, vol. 116, no. 9, pp. 1849-1864, 2016. 